\title{
Sustainability Trends, 2021 Best Paper, and Plans for 2022
}

\author{
Santanu Bandyopadhyay ${ }^{1} \cdot$ Dominic C. Y. Foo ${ }^{2} \cdot$ Raymond R. Tan ${ }^{3}$
}

Accepted: 15 December 2021 / Published online: 3 January 2022

(c) The Author(s), under exclusive licence to Springer Nature Singapore Pte Ltd. 2021

There are mixed results from the COP26 in late 2021. In spite of firmer commitments to manage methane emissions and land-use change, among others, the Glasgow Agreement states that "carbon budgets consistent with achieving the Paris Agreement temperature goal are now small and being rapidly depleted." The accord calls for planet-wide reduction of greenhouse gas (GHG) emissions through a mix of decarbonization strategies, but still falls short of what is needed to limit warming to well below $2{ }^{\circ} \mathrm{C}$. In addition to political commitments to cut national GHG emissions, the agreement also provides valuable mechanisms such as climate financing. Coupled with emerging carbon markets, in the near future, the necessary scaffolding will be in place to provide a framework to achieve the desired cuts. On the ground, scientific solutions will have to be engineered rapidly to the scale needed for significant carbon drawdown.

Energy efficiency enhancement is a time-tested strategy for reducing emissions. Process integration (PI) techniques, developed in the 1970s, are widely used in industrial sectors to maximize heat recovery and reduce costs associated with fuel consumption (Umeda et al. 1978; Linnhoff and Flower, 1978, 1982); co-benefits in the form of emissions cuts were recognized long before climate change became part of general public discourse (Dhole and Linnhoff. 1993). This year's best paper, selected from among the 62 articles published in 2021, reports yet another PI innovation. Lal et al. (2021) developed an automated retrofit targeting strategy and applied it to two industrial case studies. Their work

\footnotetext{
$\triangle$ Dominic C. Y. Foo

Dominic.Foo@nottingham.edu.my

Santanu Bandyopadhyay

santanub@iitb.ac.in

Raymond R. Tan

Raymond.Tan@dlsu.edu.ph

Indian Institute of Technology Bombay, Mumbai, India

2 University of Nottingham Malaysia Campus, Semenyih, Malaysia

3 De La Salle University, Manila, Philippines
}

demonstrates how models and algorithms can be applied to engineer solutions that make both economic and environmental sense. They also emphasize the decision support role of such techniques through the capacity to enumerate alternative solutions, which can then be examined by the final decision-makers. This key point is a critical aspect of the "big picture" in managing climate change—scientists and engineers are seldom ever the final decision-makers, but they need to effectively influence choices made by politicians, CEOs, and other decision-makers. We extend warm congratulations to Lal and his co-workers.

We shall also be making some minor changes from 2022, which are intended to improve the scope, reach, and influence of Process Integration and Optimization for Sustainability. First, we encourage all submissions that report new methods to include supporting files that will facilitate the use of these tools by readers. For example, we have noted an increasing number of decision analysis articles over the years. Such articles can be made more influential if the authors also submit implementation of the reported methodology in an appropriate software (e.g., as Excel spreadsheets or Matlab M-files). These files can be made available as supporting information on SpringerLink; alternatively, these programs and datasets can be made accessible by the authors via GitHub. Second, we will be soliciting perspective papers from renowned researchers for the purpose of mapping out future prospects of various topics covered by the scope of Process Integration and Optimization for Sustainability. Our initial target is one such paper per issue. Third, we strongly recommend our authors to share their published work in the journal via social media. Tweets containing links to papers or YouTube videos of mini-lectures based on published work can go a long way towards reaching a broader non-specialist audience, thus amplifying the potential of scientific work to contribute to the public good.

Finally, we are grateful to scholars from all over the world who have contributed-as authors, reviewers, guest editors, editorial board members, and readers- to the growth of the journal since the publication of its maiden issue in 2017. We look forward to working with you in 2022 and beyond 
to create a more sustainable future for the planet through our collective scientific outputs.

\section{References}

Dhole VR, Linnhoff B (1993) Total site targets for fuel, co-generation, emissions, and cooling. Comput Chem Eng 17:S101-S109

Lal NS, Walmsley TG, Atkins MJ, Walmsley MRW (2021) Industrial energy retrofit planning using automated retrofit targeting. Process Integration and Optimization for Sustainability 5:75-98
Linnhoff B, Flower JR (1978) Synthesis of heat exchanger networks. AIChE Journal 24:633-642

Umeda T, Itoh J, Shiroko K (1978) Heat exchange system synthesis. Chemical Engineering Progress 70-76

Publisher's note Springer Nature remains neutral with regard to jurisdictional claims in published maps and institutional affiliations. 